\title{
Correction to: Open-access database of literature derived drug-related Torsade de Pointes cases
}

Laura Krumpholz ${ }^{1}$ Barbara Wiśniowska ${ }^{1 *}$ and Sebastian Polak ${ }^{1,2^{*}}$

\section{Correction to: BMC Pharmacol Toxicol 23, 7 (2022) https://doi.org/10.1186/s40360-021-00548-0}

Following publication of the original article [1], the authors identified an error in the authors names. The given names and family names were erroneously transposed.

The incorrect authors' name are:

Given name: Krumpholz

Family name: Laura

Given name: Wiśniowska

Family name: Barbara

Given name: Polak

Family name: Sebastian

The correct authors names are:

Given name: Laura

Family name: Krumpholz

Given name: Barbara

Family name: Wiśniowska

Given name: Sebastian

Family name: Polak

The author group has been updated above and the original article [1] has been corrected.

\author{
Author details \\ ${ }^{1}$ Pharmacoepidemiology and Farmacoeconomics Unit, Faculty of Pharmacy, \\ Jagiellonian University Medical College, Medyczna 9, str., 30-688, Krakow, \\ Poland. ${ }^{2}$ Certara UK Ltd. (Simcyp Division), 1 Concourse Way, Sheffield S1 2BJ, \\ UK.
}

Published online: 31 January 2022

\author{
Reference \\ 1 Krumpholz, et al. BMC Pharmacol Toxicol. 2022;23:7. https://doi.org/10. \\ 1186/s40360-021-00548-0.
}

The original article can be found online at https://doi.org/10.1186/s40360021-00548-0.

\footnotetext{
*Correspondence: b.wisniowska@uj.edu.pl; sebastian.polak@uj.edu.pl

1 Pharmacoepidemiology and Farmacoeconomics Unit, Faculty

of Pharmacy, Jagiellonian University Medical College, Medyczna 9, str.

30-688, Krakow, Poland

Full list of author information is available at the end of the article
} 